\title{
Science and Electric Lighting
}

\section{A}

POPULAR discourse at the Blackpool meeting of the British Association was given on Friday, September 11, by Mr. C. C. Paterson He chose as his subject "Science and Electric Lighting", and illustrated his discourse by many striking and spectacular experiments. Through the medium of these experiments, he enabled the audience to picture the present outlook of the scientific worker in the field of electric lighting and how rapidly it is changing. During the last four years, the amount of light that can be obtained from a given quantity of electricity has been increased three times. During this time, it has also been demonstrated that it is possible to make lamps of which the luminous component is at least a hundred times brighter than the brightest filament previously available. These great achievements are rapidly being exploited by industry in Great Britain.

Mr. Paterson began by showing the fundamentally different methods of producing electric light by filament lamps and discharge lamps. In one we obtain light from solids and in the other from vapours. In the latter kind of lamp, the light comes from vapour made brilliantly luminous by passing electricity through it. He showed a lamp with a container for a small quantity of vapour having a volume of about a twentieth of a cubic inch. Success followed research when it was found how to pass a current through this little enclosure. The difficulty was to make the free molecules of the vapour carry electricity, but once the current started it was difficult to control it. The intensity of the light in this lamp is a measure of the vigour with which the molecules of vapour respond to the stimulation. The molecules of different vapours respond in different ways, and they show their peculiarities by the nature of the light they emit. By the spectrograph, this light can be separated into its various components, and from the point of view of the lamp maker these specify the lamp.

In the incandescent filament lamp, the filament of which is now made of tungsten, and is heated to a very high temperature, the molecules of the solid tungsten do not radiate light in the same way as vapour molecules. This is shown by the fact that the spectrum of this lamp contains all the colours shaded into one another. The spectrum of any incandescent solid or liquid is always of this type. This follows because the molecules cannot move as if they were in free space; they are constrained by the neighbouring molecules. Their light is very similar to that of the sun, which comes from incan. descent gases and vapours under extreme conditions of pressure. The light given by an incandescent filament being a rough imitation of sunlight satisfies our demands for illumination. Why therefore should we want to use something else? The reason is that the new lamps are able to give us much more light in comparison with the waste heat that is always produced.

With filament lamps the higher their temperature the more light they give, but the tungsten evaporates more rapidly the higher the temperature and thus its life is short. Research has discovered that if we coil the filament so that it occupies less space, the total convection currents will be less and the evaporation will be reduced. From this was developed the tightly coiled gas filament lamp which has been the most popular type of electric lamp for the last twenty years. In addition, by coiling the coil the efficiency can be still further increased. More than half the number of lamps now used in Great Britain for domestic purposes have coiled coil filaments and they give up to twenty per cent more light for the same consumption of electricity.

The metal tungsten out of which the filament is made is one of the toughest and most refractory of metals. It is so hard that it has to be drawn through diamond dies which have to be pierced with round holes no more than the size of a fine human hair. The wire diameter has to be correct to within 0.5 per cent, that is, five millionths of an inch. The craftsmanship of the girls who do this wire drawing is deserving of the highest praise. Mr. Paterson said that one of them described the process to him as like threading a wire you can't see through a hole that isn't there. This minute thread has then to be coiled with the greatest uniformity and equal precision, and finally the coil has to be again coiled. Out of the 3,775 turns in this spiral, not a single one must touch its neighbour, although the space between them is less than the thickness of a cigarette paper.

The enhanced efficiency of a vapour lamp is due to the absence of unwanted kinds of radiant rays. For mercury vapour lamps the effective light radiated is about three times as great for the same consumption of energy. If we had two electric lamps both using a pennyworth of electricity a day, but one giving only blue light and the other only green light, the latter appears to give more light than the former. The reason is that the green light is more useful to see with-in other words, it appears brighter. For this statement to be strictly correct, it has been presupposed that the blue light and the green light demand the same proportion of the electric power to produce them.

Tubular lamps were shown containing vapours of many kinds, and the difficulties of producing light of a satisfactory colour at a cheap rate were considered. The sodium lamp, which is the most economical, gives light of an unpleasing colour, and unfortunately no good way of correcting this colour defect has yet been invented. The neon lamp has been found very useful for floodlighting red brick buildings and for other colour effects. It is almost completely deficient in green and blue rays.

Mr. Paterson mentioned that some new investigations have opened out a new and very promising field of research. It has been discovered that if we coat the inside of a neon tube with a certain luminescent powder, the activity of the gas in the tube excites the characteristic fluorescence of this powder. It therefore gives out light of the colour we want, which, as it mixes with the red light from the neon gas, gives a series of pleasant colours very suitable for interior lighting. Hitherto it has only been found possible to excite fluorescence to an appreciable extent by direct excitation of the powder by the electrons of which the current consists, or else by means of the mercury discharge, which is very rich in ultra-violet lines. The great advance lies in the 
discovery that neon, which is comparatively poor in ultra-violet light, can by using suitable powders be made to excite luminescence. These luminescent materials will probably be largely used in electric discharge lamp lighting. They will add the missing colours to light given out by vapours and gases, thus making objects illuminated by them appear as they do in daylight.

It was found four years ago that very great yields of light could be obtained from the passage of electricity through mercury vapour, if the pressure of the vapour was increased to about one atmosphere instead of using only one hundredth of an atmosphere as in the older types of lamp. This has led to the improved lighting of hundreds of miles of streets in Britain. There are now about 15,000 street lighting posts fitted with these lamps.

Light is becoming so cheap that it is foolish not to make full use of it. Its liberal use contributes greatly to safety. It enhances the beauty of our homes and increases the efficiency of our workshops. Gardens and highways at night can be made beautiful by its use. Blackpool, perhaps more than any other town, has improved its amenities by using artificial light. Incidentally, this gives a royal welcome to its visitors.

\section{Plant Hunting and Exploration in Tibet}

\section{$\mathrm{T}$} HE second evening discourse at the Blackpool meeting of the British Association was delivered on September 15 by Capt. F. Kingdon-Ward. He said that however much we may regret some of the results of the industrialization of Britain-the destruction of forest, the urbanization of pasture land, slums, and so on-our country is in some respects a vast improvement on the England of four centuries ago. It was then a colourless land, especially during the winter. Thanks to the great interest taken in horticulture and sylviculture to-day, it is that no longer. About twelve thousand species of introduced trees, shrubs and herbs are cultivated in the opennearly ten times the total number of flowering plants which occur wild. Thus the British climate must be singularly elastic, and the plants themselves highly adaptable. Probably in no other country in the world of equal area can so many alien plants be grown. Some are difficult, but more are easy, and not a few naturalize themselves.

Tibet, the highest plateau in the world, is not as is generally supposed a complete desert. There is a gradual increase in the flora from west to east, and from north to south, corresponding with the change in the physiographical nature of the country; the vegetation slowly changes from tundra to scrub and grassland, and from scrub to forest. Naturally, the most prolific and varied flora is found in the forested south-eastern region. This flora is a mixed one. The climate varies greatly from warm temperate at the bottom of the gorges where Tibet reaches its lowest altitude at 5,000 feet, to subarctic on the high snow- clad ranges the peaks of which attain 25,000 feet. All adjacent regions-China, Indo-Malaya, the Himalaya-have contributed to the flora of Tibet. Not every plant found there is hardy in Britain, but a surprising number are. Nor is it possible to forecast whether a given plant will be hardy or not; experience enables one to make a shrewd guess, but no more. On the whole, the plants which have proved most adaptable to our gardens are those which are not found growing under extreme conditions; that is to say, the plants, not of the tundra, nor of the deep forested river gorges, nor of the highest alpine ranges, but those of the intermediate scrubclad plateau country, at 10,000-12,000 feet altitude.

Throughout the summer, one is busy collecting plants in flower. In late autumn, one starts harvesting seeds. It is not necessary to mark the plants when in flower, of which seed is required. Most plants are found over extensive areas where the climatic conditions are similar, and constant practise enables one to recognize a given plant by its fruits as readily as by its flowers. Particular plants occur in prodigious numbers; most species are at least common; the difficulty is to discover a rare plant! Capt. KingdonWard said that he could recall very fow of which he discovered but one specimen-Leycesteria crocothyrros is one of them.

Tibet has become famous as the land of the blue poppy (Meconopsis betonicifolia) and the scarlet creeping rhododendron ( $R$. repens). But it is equally the home of many other beautiful flowers, as gentians, lilies, barberries, primulas and many more.

\section{Science at the International Peace Congress}

CCIENTIFIC concern for the preservation of $\checkmark$ world peace found abundant expression at the International Peace Congress held at Brussels on September 3-6. Special commissions considered the bearing of art, science and letters, medicine, agriculture and education on the problems of peace and war, the report of the Science Sub-Commission, formed by a small but internationally representative body of scientific workers under the chairmanship of Dr. J. D. Bernal of Cambridge, being typical of the constructive attitude of the professional delegates.

This committee clearly recognized the effects of war in disintegrating the humane purpose and international character of science, and declared that scientific workers should do their utmost to strengthen international amity not only by a general determination to oppose war but also by definite practical activity. "We have to consider," it decided, "how we can best assist in preventing an immediate 